\title{
Correction to: Modeling of uniaxial compression in a 3D periodic re-entrant lattice structure
}

Li Yang ${ }^{1}$, Ola Harrysson ${ }^{1, *}$, Harvey West ${ }^{1}$, and Denis Cormier $^{2}$

${ }^{1}$ Edward P. Fitts Department of Industrial \& System Engineering, North Carolina State University, 400 Daniels Hall, 111 Lampe Dr., Raleigh, NC 27695, USA

${ }^{2}$ Department of Industrial \& System Engineering, Rochester Institute of Technology, James E. Gleanson Building, 81 Lomb Memorial Dr., Rochester, NY 14623, USA

Published online:

26 April 2020

(C) Springer Science+Business Media, LLC, part of Springer

Nature 2020
Correction to: J Mater Sci (2013)

48:1413-1422 https://doi.org/10.1007/s10853012-6892-2

In the original article, there is a typographical error in the in-line equation on page 1418 following Eq. (21). The sentence should read as follows:
In the case of a square cross section, $I=\mathrm{t}^{4} / 12$.

Publisher's Note Springer Nature remains neutral with regard to jurisdictional claims in published maps and institutional affiliations.

The original article can be found online at https:/ / doi.org/10.1007/s10853-012-6892-2.

Address correspondence to E-mail: harrysson@ncsu.edu 